analysis is correct. Very infrequently does one now hear of renal units being oversubscribed with patients in contrast to conditions of 10 years ago. I suspect that you are correct in suggesting that potential patients are not referred because it is believed that facilities are too limited. Over the past four years I have had the opportunity of selecting dialysis patients and have declined only five. One was over 70 , three had advanced vascular disease, and one was a heroin addict. The point is clear; the profession, like the media, think there are insufficient kidney machines. You have profitably indicated that insufficient patients are referred.

Although the number of units and equipment therein is adequate for the number of patients currently treated, maximal use of dialysis facilities is limited by the availability of trained nurses. Some units can dialyse only by day for lack of nurses. Rather than the provision of more machines, consideration should be given to ways of attracting nurses to work in renal units and funds allocated for an increase in their salaries.

Roger GABRIEL

Department of Renal Medicine,

St Mary's Hospital,
London W2

SIR,-Your leading article (25 November, p 1449), while giving an admirable objective review of the selection of patients for dialysis and transplantation as practised in the United States of America, Japan, Continental countries, and Britain, does not take into consideration the wide variation in the organisation of the health systems in these countries. It is justifiable to measure strength with our partners, but any direct comparison made would not be valid, for the nephrological services provided by any of these countries is roughly correlated to the nation's wealth. ${ }^{1}$ Whereas in some countries it may be possible to treat schizophrenia and psoriasis through haemodialysis, the same becomes ethically unjustifiable in a country which lacks finances for its basic services.

Realising the shortcomings of the home dialysis programme, I feel we should not jump on the bandwagon and go flat out to open centres for, as you wisely call it, "hospital dialysis in, for example, so-called satellite or self-care units." Confusing terminology has evolved to describe such units in order to satisfy the physicians' whims. As I see it, home dialysis is true self-care, whereas other modes of therapy-namely, limited care, minimal care, assisted care, and satellite dialysis, are all various other names for hospital dialysis. I have suggested yet another form of centre dialysis-that is, "community dialysis." by a trained paramedical person (helper) outside the hospitals. Such trained personnel are already available in Britain in the form of artificial kidney assistants. Learning from the American experience, we do run a risk of

Comparison of dialysis population with transplanted patients ${ }^{4}$

\begin{tabular}{|c|c|c|c|c|c|c|c|}
\hline \multirow[t]{2}{*}{ Country } & \multirow{2}{*}{$\begin{array}{c}\text { Population } \\
\text { (millions) }\end{array}$} & \multicolumn{3}{|c|}{ No of patients on dialysis } & \multicolumn{3}{|c|}{$\begin{array}{l}\text { No of patients with functioning } \\
\text { transplant }\end{array}$} \\
\hline & & 1975 & 1976 & 1977 & 1975 & 1976 & 1977 \\
\hline $\begin{array}{l}\text { West } \\
\text { Germany } \\
\text { France } \\
\text { Italy } \\
\text { U.K. }\end{array}$ & $\begin{array}{l}62 \\
52 \\
56 \\
56\end{array}$ & $\begin{array}{l}5056 \\
4650 \\
4189 \\
2168\end{array}$ & $\begin{array}{l}5946 \\
5650 \\
5265 \\
2423\end{array}$ & $\begin{array}{l}7357 \\
6600 \\
5713 \\
2576\end{array}$ & $\begin{array}{r}299 \\
686 \\
288 \\
1250\end{array}$ & $\begin{array}{r}425 \\
841 \\
401 \\
1501\end{array}$ & $\begin{array}{r}478 \\
940 \\
503 \\
1785\end{array}$ \\
\hline
\end{tabular}

having on our hands expensive doctor-cumnurse-supervised satellite units. It is cheaper to dialyse with the aid of a paid helper at home than to use hospital facilities. ${ }^{3}$

Whether the increase in hospital dialysis population would necessarily result in an increased pool of renal transplanted patients is debatable. In Continental countries, in with an ever-increasing population of patients on hospital dialysis, their transplant patient pool is no higher than ours (see table below).

The UK home dialysis service has developed into an enviable institution which should not only be maintained but allowed to progress at the current rate.

Renal Dialysis Unit,

RASHEED AHMAD

Sefton General Hospital, Liverpool

Parkin, D M, in Living with Renal Failure, ed J L Anderton, F M Parsons, and D E Jones. Lancaster, MTP, 1978 .

Symposium, in United Kingdom and Ireland Dialysis 1975 .

${ }^{3}$ Kolff, W J, Artificial Organs, 1978, 1, 8.

roceedings of the European Dialysis and Transplantation Association, 1976, 13, 8, 1977, 14, 16, and 1978,

\section{Behcet's disease}

SIR,-We noted with interest your leading article on Behçet's disease (22 July, p 234). We agree that the majority of these patients eventually present in rheumatology clinics. The high incidence of the disease in the Middle East is supported by our experience. One of us (MM) saw one new patient with Behçet's disease in one year while working in a large rheumatology research centre in Glasgow Royal Infirmary. In the past 12 months in Riyadh we have seen 14 patients with Behçet's disease. They all came from two unrelated families. The pattern of the disease was unusual in that there was strong presumptive evidence of an infective aetiology and of the disease being susceptible to hormonal influence.

All those affected had the classical features of the disease-that is, painful oral ulcers with genital ulceration, iritis, and asymmetrical arthritis.

In the first family the father was initially affected and after one year of marriage his wife, who was unrelated and previously healthy, developed the disease. She noticed that pregnancy caused severe and prolonged exacerbations of her arthritis and ulcers. Only at the menopause did she become free from children, eight of whom developed Behçet's disease. Six daughters and two sons are affected and all developed the disease after puberty. Two of her daughters have married and after approximately one year of marriage their previously healthy husbands have developed the disease. Neither were consanguineous marriages. Both women have spite of the liberal organ donation laws and all symptoms of the disease. She had 10 noticed that their symptoms are aggravated by the contraceptive pill and pregnancy.

In the second family, which is completely unrelated to the first, a woman developed the disease five years after marriage to a man with active Behçet's disease. She also has observed that pregnancy makes her symptoms very much worse. The pattern of the disease in the two families would support the hypothesis of the disease being infective in origin and, in view of the long incubation period, infection with a slow virus is a possibility. So far as we are aware the influence of pregnancy and the contraceptive pill on the course of the disease has not been observed before.

Department of Medicine,

MONIR MADKOUR

Department of Medicin
Al-Kharj Hospital,

AIDA KUDWAH

Riyadh, Saudi Arabia

\section{Retroperitoneal fibrosis after treatment} with atenolol

SIR,-We wish to report the following illness which occurred in a patient receiving treatment with the beta-blocker atenolol (Tenormin).

A 68-year-old woman consulted her general practitioner because of vague ill health, was found to be hypertensive, and was started on atenolol $100 \mathrm{mg}$ daily. Six months later she was admitted to hospital because of vomiting and abdominal pain, but the only abnormality found on investigation was a high erythrocyte sedimentation rate $(114 \mathrm{~mm}$ in $1 \mathrm{~h})$. The blood urea concentration was $7.3 \mathrm{mmol} / 1$ $(44 \mathrm{mg} / 100 \mathrm{ml})$ at this time. Her symptoms settled spontaneously but three months later she was readmitted in an acute confusional state. Investigations showed a blood urea concentration of $37.2 \mathrm{mmol} / 1(224 \mathrm{mg} / 100 \mathrm{ml})$ and dilated upper renal tracts on intravenous pyelography. Laparotomy showed extensive retroperitoneal fibrosis, and after bilateral ureterolysis her mental state and renal function returned to normal.

The only other drugs taken by the patient before this illness were oral iron preparations, metoclopramide, and ibuprofen. We report this case because of the established relationship between the earlier beta-blocker practolol and similar types of sclerosing fibroblastic reaction.

C C DOHERTY MaRY G MCGEOWN R A DONALDSON

\section{Renal Unit,}

Belfast City Hospital, Belfast

\section{Hazards of sulphinpyrazone}

SIR,-Recent claims that the administration of sulphinpyrazone (Anturan) can markedly improve the survival rate after recovery from acute myocardial infarction are based on a single large multicentre trial in North America. ${ }^{12}$ Since this drug is now being extensively advertised, it is important to be aware of its hazards.

We wish to report the occurrence of a severe gastrointestinal haemorrhage in a man of 63 with a history of hypertension, stroke, and myocardial infarction who was on concurrent anticoagulant therapy. Prior to the introduction by his general practitioner of sulphinpyrazone $200 \mathrm{mg}$ four times daily his prothrombin time had been maintained within the therapeutic range on warfarin $8 \mathrm{mg}$ daily. One week after starting sulphinpyrazone he 